\title{
Several Aspects of Information Flows in PLM
}

\author{
Hong-Bae Jun $^{1}$ and Dimitris Kiritsis ${ }^{2}$ \\ ${ }^{1}$ Hongik University, Dept. of Industrial Engineering, Seoul, Korea \\ hongbae.jun@hongik.ac.kr \\ ${ }^{2}$ EPFL, Dept. of Mechanical Engineering, Lausanne, Switzerland \\ dimitris.kiritsis@epfl.ch
}

\begin{abstract}
There are lots of activities in the product lifecycle, which are grouped into three main phases: beginning of life (BOL), middle of life (MOL), and end of life (EOL). Thanks to recent emerging technologies, information flows of whole product lifecycle can be visible and controllable. The PLM under this environment allows all actors of the whole product lifecycle to access, manage, and control information flows. These flows can be used to streamline several operations of BOL, MOL and EOL. In order to recognize the benefit of these information flows, first of all, it is necessary to comprehend them in detail. For this purpose, this study will deal with several aspects of information flows in PLM. It will clarify the concept of information flows and identify which product lifecycle information are required for streamlining lifecycle operations, and classify them into several types depending on their characteristics.
\end{abstract}

Keywords: BOL, MOL, EOL, closed-loop PLM, information flows.

\section{Introduction}

Recently, the product lifecycle management (PLM) has been in the spotlight. The PLM is a new strategic approach to manage product-related information efficiently over the whole product lifecycle (Ameri and Dutta 2004). In general, the product lifecycle is defined as "a series of stages that a product goes through from its concept generation to its disposal." It can be decomposed into three main phases: Beginning of Life (BOL), including Design and Production, Middle-of-Life (MOL), including Use, Service and Maintenance, and End-of-Life (EOL) where products are recollected, disassembled, remanufactured, recycled, reused, or disposed of.

The PLM is ideally an information processing system (Saaksvuori and Immonen 2002). It supports the management of all information such as CAD drawings, technical documents, and structured and unstructured information created, changed, transferred, stored, managed, and converted by along the lifecycle of a product, from its design to end of life. It becomes the backbone for managing product related information in an enterprise. Physically, product data and information are dispersed along a variety of information systems, generated and used in the diverse phases of the lifecycle by many different actors (Terzi et al. 2005). Thus, PLM should enable several internal and external actors (i.e. stakeholders) to do collaborative creation, 
modification, dissemination, and search of information throughout product lifecycle. It entails modeling, searching, manipulating, exchanging, and using of lifecycle information over the whole lifecycle. As Rachuri et al. (2008) and Xu et al. (2009) mentioned, the scope of information to be managed increases as the product lifecycle evolves. As a result, a great deal of lifecycle information is generated during the whole product lifecycle. Since the information is usually created and consumed by various stakeholders in a certain sequence, lots of information flows are generated. Because of emerging information and communication technologies, it is no doubt that there are more complex information flows over the whole lifecycle. As Ouertani et al. (2011) mentioned, querying and sharing product knowledge is becoming a key issue in enterprise information systems. Hence, the success of PLM lies in identifying what kind of information are available in the other phase, and how we can use them in order to streamline business processes.

Currently, there is the lack of study on information flows to be identified across product lifecycle operations. Although some studies dealt with information flows in PLM, many of them addressed the framework or protocol for communicating information flows, not information flows themselves. As a result, very little attention has been paid to clarifying the product lifecycle information flow. The unavailability of explicit flows of product lifecycle information leads to a certain degree of inefficiency in performing lifecycle operations. Thus, the methods to efficiently represent, control, and search information flows are critical. It requires the identification of information flows and their efficient management, which can play an important role in analyzing and making decisions of several operational issues in the product lifecycle.

To this end, first and foremost, this study focuses on clarifying the concept of product lifecycle information flows from several viewpoints. This study is organized as follows. Section 2 addresses the previous studies related to product lifecycle information. Section 3 deals with several aspects of lifecycle information flow. Finally, some discussion points are addressed with conclusion.

\section{Previous Study}

This section summarizes the part of previous studies related to product lifecycle information and also introduces the PROMISE project with its main concept, the closed-loop PLM, where closed information flows had been addressed.

\subsection{Previous Studies on Product Lifecycle Information}

Until so far some literatures dealt with lifecycle information model itself or how to capture lifecycle information or data, rather than on information flows themselves. For example, Goncharenko et al. (1999) proposed an approach to collect and utilize product feedback information throughout product lifecycle. Harrison and McFarlane (2004) addressed the information required to support various decisions to be taken along a product lifecycle. They mentioned the characteristics of lifecycle information in terms of information quality as follows: uniqueness, completeness, timeliness, and 
accuracy. Furthermore, Terzi et al. (2007) dealt with the product traceability problem concerning with the management of the identification of a product along its lifecycle. They presented a reference meta model with the concept, 'product holon' that merges product physical part with product information needed for tracing its life. In addition, Främling et al. (2007) analyzed and compared three approaches (EPC Network, DIALOG and WWAI) for providing a linking mechanism to product information that may be stored in backend systems of different organizations. Recently, Liu et al. (2009) addressed various information related to product based on previous PLM literature survey. Xiao et al. (2010) proposed a 4D (prototype system, geometry, task, and lifecycle dimension) view model for sharing and managing product lifecycle information, especially, simulation data. They mentioned that product lifecycle information could be described in aspects of time and space.

On the other hand, some literatures concentrated on the modelling of product lifecycle information. For example, Jun et al. (2005, 2007) applied the resource description framework (RDF) to represent and search the meta-data of product lifecycle with a modelling procedure. Jun et al. (2009) also introduced key information required for capturing closed feedback flows among three main lifecycle phases with the RFID application framework in PLM. Furthermore, Sudarsan et al. (2005) proposed a product information modeling framework to support the full range of PLM information needs, based on the NIST Core Product Model (CPM) and its extensions, the Open Assembly Model (OAM), the Design-Analysis Integration model (DAIM) and the Product Family Evolution Model (PFEM). Rachuri et al. (2008) also proposed a model of information flows in PLM. They dealt with the protocol for communicating information among PLM stakeholders. They classified content of product information used by various stakeholders in a product lifecycle into three main categories: form information, functional information, and lifecycle information. In addition, Xu et al. (2009) proposed a framework and methodology to model three principle information loops in wireless technology-enabled closed-loop supply chains (CLSC). They addressed the models of three information flows (MOL to MOL, MOL to EOL, All to BOL product design), focusing on dynamic information related flows and tracking activities. In addition to the traditional forward flow of products to customers, they considered the acquisition and return flows of products for functional rehabilitation or value recovery.

\subsection{PROMISE Project and Closed-Loop PLM}

For tracking and utilizing the lifecycle information throughout the whole product lifecycle, the concept of closed-loop PLM had been proposed in the PROduct lifecycle Management and Information tracking using Smart Embedded systems (PROMISE) project (Kiritsis et al. 2007). The main objective of PROMISE project is to develop a new generation of product information tracking and flow management system. In general, it is acknowledged that the information flow breaks down after the delivery of the product to the customer. The fact that the information flow is in most cases interrupted shortly after product sale restricts the feedback of data, information and knowledge, from service and maintenance and recycling experts back to 
designers and producers. However, with the recent advances of emerging technologies, the whole product lifecycle can be visible and controllable. In PROMISE, Product Embedded Information Devices (PEID) such as RFID tag and on-board computer with associated firmware, software components, and tools, had been used for this purpose. This resulted in closed-loop information flows during the whole product lifecycle, which appeared in 10 industrial applications of PROMISE.

\section{Product Lifecycle Information Flows}

In general, information is typically processed (or generated) in a certain sequence. This is referred to as the information flow (Schneider and Marquardt 2002). Product lifecycle information has the following characteristics.

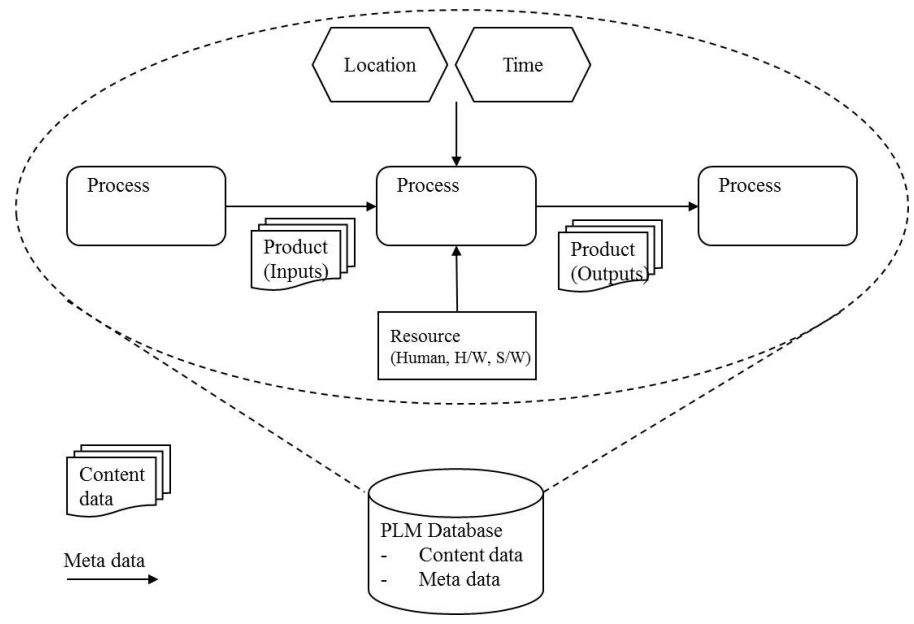

Fig. 1. Schema of product lifecycle information flow

\subsection{Characteristics of Lifecycle Information Flow}

(1) It Occurs When Lifecycle Information Generated at the Past Period Are Changed or Referred to by Lifecycle Actors

During lifecycle, there are huge amount of lifecycle data related to product, process, resource, and time. They can be divided into content and meta data depending on their characteristics. They cannot occur independently and are related each other. The content data such as drawings, engineering and technical documents are created, modified, referred to, and deleted during lifecycle period, which generate the relations of product, process, resource, and time. These relations are called meta data. The combination of content and meta data becomes lifecycle information. It can be represented with the PPRLT (Product, Process, Resource, Location, and Time) relation as shown in Figure 1. Here the PPR relation is frequently mentioned in several previous literatures for representing enterprise information. In Figure 1, each entity of 
PPRLT is just data, which describes only a part of what happened during lifecycle based on $5 \mathrm{~W} 1 \mathrm{H}$; it provides no judgment or interpretation and no sustainable basis of action. However, PPRT relations create information since they can give some useful meanings. During lifecycle operation, all lifecycle content data are processed throughout the PPRT relations. Hence, lifecycle information includes relevant product (input/output of process), process to deal with the product, and resource to support the process. The resource includes the following: human, hardware (facility), software (information system), and PLM agent. Here, the PLM agent has the role in processing lifecycle information and transmitting them into some information systems, that is, creating information flow. For example, maintenance engineer with some smart device like PDA or Product embedded information device is a PLM agent. Product lifecycle information flow occurs when the lifecycle information generated at the past period are changed or referred to by several lifecycle actors.

\section{(2) It Has Closed-Loops, and Is Horizontally and Vertically Closed}

It has closed-loops since generated information in a certain process can be used in any other lifecycle processes, and updated information can go back to the process for reuse. There are two kinds of closed information flows in the PLM: forward and backward. For the example of forward flows, BOL information can be used to streamline processes of MOL and EOL. Service and maintenance and recycling experts will be assisted in their work by having an up-to-date report about the status of the product during MOL and product design specification made from BOL phase. Also, recyclers/reusers will be able to obtain accurate information about 'value materials' and 'disassembly instruction' of EOL products from product design information. On the other hand, for the example of backward flows, MOL and EOL information can also go back to the designer and producer for improvement of BOL decisions. For example, designers will be provided with product usage data about the modes of use and conditions of retirement and disposal of their product, and thus improve product designs towards product lifecycle quality goals. It indicates that the information flow is horizontally closed over the whole product lifecycle. In addition, information flow is vertically closed. This means that in a certain process, based on gathered data related to resource, process, and product, we can analyze product related information and take some decisions on optimization of processes with support of some information systems, which will affect data gathering again.

\section{(3) It Is Accumulated and Transformed}

As the lifecycle proceeds, lifecycle information and its flows are more and more accumulated. With the accumulated lifecycle information and its flows, we can see how content data are updated and reused for other processes. In addition, it is possible to find some clues for solving problems or defects encountered in product content data. Although each information or information flow itself may be incomplete for capturing any meaning, the accumulated lifecycle information can be transformed into knowledge and usefully applied for streamlining lifecycle operations. Throughout analyzing, synthesizing, comparing, tracking, and tracing accumulated information flows, we can derive or deduce certain knowledge, e.g. on product status or the source of (bad) quality. 


\section{(4) It Is Initiated by Business Drivers and Used in Appropriate Information System}

Information flows can be initiated by several business drivers of lifecycle operations such as incorporating voice of customer into design process, improving internal engineering collaboration/concurrent engineering, improving supply chain collaboration, establishing systematic knowledge capture and reuse, product design improvement using product usage data, fast reconfiguration of a production system, efficient warehouse management, efficient production logistics, predictive maintenance, MOL maintenance/service process optimization, EOL product logistics/waste stream management, and EOL product recovery decision making, and so on. Some business drivers are already considered in the PLM implementation. Others can be newly provided after the implementation of PLM by the requests of stakeholders. In any case, business drivers make information flows generated. The generated information flows are used in appropriate information system for streamlining lifecycle operations

\subsection{Classification of Information Flows}

In this study, to gain a clear understanding of information flows in PLM, we classify them as follows. First, according to the direction of closed-loops, they can be classified into vertically closed and horizontally closed information flows.: (1) Vertically closed, and (2) Horizontally closed. At first, as the lifecycle is evolving, vertical information flows are generated. Then, by the request of business applications, horizontal information flows are generated. Regarding horizontal information flows, according to the direction of lifecycle phases, they can be classified into forward and backward information flows.

\section{- $\quad$ Forward Information Flow}

BOL to MOL: In general, there are lots of information flows from BOL to MOL since product design and production information are required to deliver products to customers and keep the use of products without any problems. Product usage (or operation) and maintenance period (i.e. MOL phase) is longer than any other lifecycle phases. Thus, technical manuals of products produced at BOL should be kept up to date until the end of product usage. Furthermore, product information for maintenance and spare parts should be accessible at any time. To this end, 'BOL to MOL' information flows are generated. This flow becomes more important since the service-oriented engineering has been highlighted.

MOL to EOL: Recently, the importance of product recovery process has been increasing since return rate of products rises up due to the expansion of online product purchasing market and strict environmental regulation on products. These motivations make companies have much interest in effective EOL management, which requires MOL to EOL information flows. Owing to various information technologies, a PLM system can gather accurate data related to product usage data during MOL phase, e.g. repair history data, mileage, current status of component, used time, etc. Based on gathered data, at the collecting and dismantling phase of EOL products, EOL product experts in the PLM system can predict degradation status and remaining 
life time of parts or components. With the information, at the inspection phase, the dismantler can do EOL product recovery optimization, in other words, deciding suitable EOL recovery options such as recycle, reuse, remanufacturing, and disposal, with the objective of maximizing values of EOL products considering product status. To this end, 'MOL to EOL' information flows are generated.

BOL to EOL: A PLM system can gather accurate data related to product lifecycle history at the collecting and dismantling phase of EOL products, e.g. material recycling can be significantly improved because recyclers and re-users can obtain accurate information about "value parts and materials" arriving via EOL routes: which components they consist of, what materials they contain, who manufactured them, and other data that facilitate reuse of materials, components and parts, which can be provided from BOL phase. To this end, 'BOL to EOL' information flows should be generated.

\section{- Backward Information Flow (Feedback)}

Most forward information flows can be directly used as inputs for streamlining the operations of next phases. However, some of them such as feedbacks from MOL and EOL to BOL must be indirect links because they take some times so that they do not directly affect the design and production of the same products that were considered at BOL. However, the feedback information can be used as knowledge for improving the design and production of the same or similar types of next-phased products.

MOL to BOL: In BOL, designers and producers will receive feedback about detailed product information from distributors, maintenance/service engineers, or customers on product usage, about the conditions of retirement, and disposal of their products. Therefore, they will be able to exploit expertise and know-how of other actors in the product lifecycle. For example, mission profile data and maintenance data of products during MOL phase can be a good reference data for improving the design of next similar types of products. We can apply collected product usage data to improve the design of next-phased products via design for reliability. It will also help to enhance production processes and systems. Furthermore, we can gain marketing advantage from improved knowledge of how users utilize a product (Xu et al. 2009).

EOL to MOL: Optimization of EOL recovery decision also provides useful information to remanufacturers for making an efficient remanufacturing plan in advance. Furthermore, logistics engineers can improve logistics at EOL (reverse logistics) from collecting to remanufacturing, reuse or disposal. They can get supply volume data for recycle, reuse, remanufacturing, and disposal products in advance from the EOL decision. They can also know demand data for EOL products, e.g. a number of products to be collected, collecting locations, etc. With this information, they can make the best collecting and redistribution plan (reverse logistics plan) with the objective of minimizing total logistics operation cost.

EOL to BOL: In addition, EOL product recovery decision data and product status at EOL dismantling can give useful information to product designers for improving product design with several purposes, e.g. design for reliability, reuse, recycle, and so on. For example, the field data from EOL disassembly activities can act as a source of knowledge to design for improved cost efficiency of disassembly (Xu et al. 2009).

Table 1 and 2 show the information flows and relevant applications with necessary information. 
Table 1. Information flow (forward)

\begin{tabular}{|c|c|c|c|}
\hline Direction & Business drivers & & Information \\
\hline \multirow[t]{3}{*}{$\begin{array}{ll}\text { BOL } & \text { to } \\
\text { MOL }\end{array}$} & $\begin{array}{l}\text { Improving design and } \\
\text { manufacturing colla- } \\
\text { boration }\end{array}$ & BOM information & $\begin{array}{l}\text { Product ID, product structure, part } \\
\text { ID, component ID prod- } \\
\text { uct/part/component design specifica- } \\
\text { tion, etc. }\end{array}$ \\
\hline & $\begin{array}{l}\text { Improving service } \\
\text { collaboration }\end{array}$ & $\begin{array}{l}\text { Information for } \\
\text { maintenance/service }\end{array}$ & $\begin{array}{l}\text { Spare part ID list, price of spare part, } \\
\text { maintenance/service instructions, etc. }\end{array}$ \\
\hline & & $\begin{array}{l}\text { Production informa- } \\
\text { tion }\end{array}$ & $\begin{array}{l}\text { Assemble/disassemble instruction, } \\
\text { production specifications production } \\
\text { history data, production routing data, } \\
\text { production plan, inventory status, etc. }\end{array}$ \\
\hline \multirow[t]{2}{*}{$\begin{array}{l}\text { BOL } \\
\text { EOL }\end{array}$} & \multirow[t]{2}{*}{$\begin{array}{l}\text { Improving product } \\
\text { reuse and eliminating } \\
\text { environmental effects }\end{array}$} & Product information & $\begin{array}{l}\text { Material information, BOM, } \\
\text { part/component cost, disassemble } \\
\text { instruction, assembly information for } \\
\text { remanufacturing, etc. }\end{array}$ \\
\hline & & $\begin{array}{l}\text { Production informa- } \\
\text { tion }\end{array}$ & $\begin{array}{l}\text { Production date, lot ID, production } \\
\text { location, etc. }\end{array}$ \\
\hline \multirow[t]{4}{*}{$\begin{array}{l}\text { MOL to } \\
\text { EOL }\end{array}$} & \multirow[t]{4}{*}{$\begin{array}{l}\text { Improving product } \\
\text { reuse }\end{array}$} & $\begin{array}{l}\text { Maintenance history } \\
\text { information }\end{array}$ & $\begin{array}{l}\text { Number of breakdowns, } \\
\text { parts/components' IDs in problem, } \\
\text { installed date, maintenance engineers' } \\
\text { IDs, list of replaced parts, aging } \\
\text { statistics after substitution, mainten- } \\
\text { ance cost, etc. }\end{array}$ \\
\hline & & $\begin{array}{l}\text { Product status in- } \\
\text { formation }\end{array}$ & $\begin{array}{l}\text { Degree of quality of each component, } \\
\text { performance definition, etc. }\end{array}$ \\
\hline & & $\begin{array}{l}\text { Usage environment } \\
\text { information }\end{array}$ & $\begin{array}{l}\text { Usage condition (e.g. average hu- } \\
\text { midity, internal/external temperature), } \\
\text { user mission profile, usage time, etc. }\end{array}$ \\
\hline & & Updated BOM & $\begin{array}{l}\text { Updated BOM by repairing or chang- } \\
\text { ing parts and components, etc. }\end{array}$ \\
\hline
\end{tabular}

Table 2. Information flow (backward)

\begin{tabular}{|c|c|c|c|}
\hline Direction & \multirow{4}{*}{\begin{tabular}{l}
\multicolumn{1}{c}{ Business drivers } \\
Incorporating voice of \\
customer into design \\
process
\end{tabular}} & \multicolumn{2}{|r|}{ Information } \\
\hline \multirow[t]{3}{*}{$\begin{array}{l}\text { MOL to } \\
\text { BOL }\end{array}$} & & $\begin{array}{l}\text { Maintenance and } \\
\text { failure information } \\
\text { for design improve- } \\
\text { ment }\end{array}$ & $\begin{array}{l}\text { Ease of maintenance/service, relia- } \\
\text { bility problems, maintenance date, } \\
\text { frequency of maintenance, MTBF, } \\
\text { MTTR, failure rate, critical compo- } \\
\text { nent list, root causes, etc. }\end{array}$ \\
\hline & & $\begin{array}{l}\text { Technical customer } \\
\text { support information }\end{array}$ & $\begin{array}{l}\text { Customer complaints, customer } \\
\text { profiles, response, etc. }\end{array}$ \\
\hline & & $\begin{array}{l}\text { Usage environment } \\
\text { information }\end{array}$ & $\begin{array}{l}\text { Usage condition (e.g. average hu- } \\
\text { midity, internal/external tempera- } \\
\text { ture), user mission profile, usage } \\
\text { time, etc. }\end{array}$ \\
\hline $\begin{array}{l}\text { EOL } \\
\text { MOL }\end{array}$ & $\begin{array}{l}\text { Improving supply } \\
\text { chain collaboration }\end{array}$ & $\begin{array}{l}\text { Recycling/reusing } \\
\text { part or component } \\
\text { information }\end{array}$ & $\begin{array}{l}\text { Reuse part or component, remanu- } \\
\text { facturing information, quality of } \\
\text { remanufacturing part or component, } \\
\text { etc. }\end{array}$ \\
\hline \multirow[t]{3}{*}{$\begin{array}{l}\text { EOL to } \\
\text { BOL }\end{array}$} & \multirow[t]{3}{*}{$\begin{array}{l}\text { Incorporating voice of } \\
\text { customer into design } \\
\text { process }\end{array}$} & $\begin{array}{l}\text { EOL product status } \\
\text { information }\end{array}$ & $\begin{array}{l}\text { Product/part/component life-time, } \\
\text { recycling/reuse rate of each compo- } \\
\text { nent or part, etc. }\end{array}$ \\
\hline & & $\begin{array}{l}\text { Dismantling infor- } \\
\text { mation }\end{array}$ & $\begin{array}{l}\text { Ease to disassemble, reuse or recy- } \\
\text { cling value, disassembly cost, rema- } \\
\text { nufacturing cost, disposal cost, etc. }\end{array}$ \\
\hline & & $\begin{array}{l}\text { Environmental } \\
\text { effects information }\end{array}$ & $\begin{array}{l}\text { Material recycle rate, environmental } \\
\text { hazard information, etc. }\end{array}$ \\
\hline
\end{tabular}




\subsection{Discussion}

The lifecycle information flows in PLM may be explicit or implicit. When implementing PLM, according to functions required in a company, some information flows are designed and explicitly built for monitoring them. However, some ad-hoc information flows may be generated later by internal or external stakeholders. In any case, it is important to have the infrastructure for allowing those information flows without any technical problem during product lifecycle. That is, PLM should be the backbone structure of information flows. To this end, there are several issues to be considered. First, to facilitate several information flows, for each lifecycle phase, it is critical to gather lifecycle information. During BOL phase, it seems that lifecycle information can be gathered without any problems thanks to several common information systems such as CAD/CAM, PDM, and MES. The problem is that most lifecycle information has been lost after sales. However, according to emerging wireless communication and sensor technologies such as RFID system, Bluetooth, global positioning system (GPS), and wireless sensor networks (WSN), it becomes possible to gather lifecycle information during product usage period. Second, with an understanding of how people work collaboratively we try to gain insight into how lifecycle information flows through a company during product lifecycle. For the success of PLM, one important point is that not only explicit flows but also implicit flows of lifecycle information generated during off-line tasks should be manipulated in PLM. In this sense, modeling for product lifecycle information and its flow is also important. To this end, useful diagrammatic tools for information flow, e.g. RDF, would be required. Third, several tools and methods for supporting processes should be integrated with information flows. For example, quality function deployment (QFD) method, failure mode and effect analysis (FMEA), and design for X-ability (DFX) should be integrated with forward and backward information flows, respectively. Fourth, information flow is simply transmission of information from one place to another. Over lifecycle, a huge amount of product lifecycle information are generated and modified, and reused for several applications within or through a company. Hence, product lifecycle information should be available at any time and any place with proper format. Furthermore, timely and accurate information is a prerequisite to obtain a competitive advantage to meet this challenge. To this end, infrastructure and methods to keep consistency and accuracy of information and to facilitate collaborations among different participants are critical. Finally, it is necessary to efficiently find information stored in different locations, source systems and formats in one search.

\section{Conclusion}

This study has dealt with several aspects of information flows in PLM. It addressed the concept of lifecycle information flows and identified which product lifecycle information are required for streamlining lifecycle operations, and classified them into several types depending on their characteristics. It is worthwhile to study what information flow is and how information flow is created and used during product life- 
cycle. By understanding the value of lifecycle information flows, better decisions can be made for streamlining product lifecycle operations.

Since this study just dealt with some parts of the study on product lifecycle information flows, the following can be considered as future research works. First, one can investigate more detailed characteristics of information flows. It may also be the challenging issues to develop the ontology-based product information flows sharing. Furthermore, someone may concern how product lifecycle information flows can be traced over the whole lifecycle. Analysis on benefits of information flows can be used to doing ROI analysis of PLM. In addition, it can be one challenging issue to look into the information flows of PLM with social network analysis and mobile/cloud computing environment.

Acknowledgements. This research was supported by Basic Science Research Program through the National Research Foundation of Korea (NRF) funded by the Ministry of Education, Science and Technology (2011C103401).

\section{References}

1. Ameri, F., Dutta, D.: Product Lifecycle Management: Needs, Concepts and Components. Technical Report, Product Lifecycle Management Development Consortium, PLMDCTR3-2004 (2004)

2. Kiritsis, D., Jun, H.-B., Xirouchakis, P.: Closing product information loops with product embedded information devices: RFID Technology and Applications, Models and Metrics, RFID technology and Applications. Cambridge University Press (2007)

3. Främling, K., Harrison, M., Brusey, J.: Requirements on unique identifiers for managing product lifecycle information: comparison of alternative approaches. International Journal of Computer Integrated Manufacturing 20(7) (2007)

4. Goncharenko, I., Kryssanov, V.V., Tamaki, H.: An agent-based approach for collecting and utilizing design information throughout the product life cycle. In: Proceedings of the 7th IEEE International Conference on Emerging Technologies and Factory Automation (ETFA1999), Barcelona, Spain, vol. 1, pp. 175-182 (1999)

5. Harrison, M., McFarlane, D.: Information management in the product lifecycle-the role of networked RFID (2004)

6. Jun, H.-B., Kiritsis, D., Xirouchakis, P.: Product lifecycle information modeling with RDF. In: Proceedings of International Conference on Product Lifecycle Management (PLM), Lyon, France, pp. 44-54 (2005)

7. Jun, H.-B., Kiritsis, D., Xirouchakis, P.: Product life-cycle metadata modeling ad its application with RDF. IEEE Transactions on Knowledge and Data Engineering 19(12), 16801693 (2007)

8. Jun, H.-B., Shin, J.-H., Kim, Y.-S., Kiritsis, D., Xirouchakis, P.: A framework for RFID applications in product lifecycle management. International Journal of Computer Integrated Manufacturing. 22(7), 595-615 (2009)

9. Liu, W., Zeng, Y., Maletz, M., Brisson, D.: Product Lifecycle management: A review. In: Proceedings of ASME 2009 International Design Engineering Technical Conferences \& Computers and Information in Engineering Conference, San Diego, USA (2009) 
10. Ouertani, M.J., Baina, S., Gzara, L., Morei, G.: Traceability and management of dispersed product knowledge during design and manufacturing. Computer-Aided Design 43(5), 546$562(2011)$

11. Qiao, G.: Manufacturing information integration in product lifecycle management (PLM) challenge. In: Proceedings of ASME 2004 International Design Engineering Technical Conferences and Computers and Information in Engineering Conference (IDETC/CIE 2004), vol. 4 (2004)

12. Rachuri, S., Subrahmanian, E., Bouras, A., Fenves, S.J., Foufou, S., Sriram, R.D.: Information sharing and exchange in the context of product lifecycle management: Role of standards. Computer-Aided Design 40, 789-800 (2008)

13. Saaksvuori, A., Immonen, A.: Product Lifecycle Management. Springer (2002)

14. Schneider, R., Marquardt, W.: Information technology support in the chemical process design life cycle. Chemical Engineering Science 57, 1763-1792 (2002)

15. Sudarsan, R., Fenves, S.J., Sriram, R.D., Wang, F.: A product information modeling framework for product lifecycle management. Computer-aided Design 37, 1399-1411 (2005)

16. Terzi, S., Panetto, H., Morel, G., Garetti, M.: A holonic metamodel for product traceability in PLM. International Journal of Product Lifecycle Management 2(3), 253-289 (2007)

17. Xiao, S., Xudong, C., Li, Z., Guanghong, G.: Modeling framework for product lifecycle information. Simulation Modeling Practice and Theory 18, 1080-1091 (2010)

18. Xu, D.F., Li, Q., Jun, H.-B., Browne, J., Chen, Y.L., Kiritsis, D.: Modelling for product information tracking and feedback via wireless technology in closed-loop supply chains. International Journal of Computer Integrated Manufacturing 22(7), 648-670 (2009) 